\title{
Leibniz, spinozismo e misticismo
}

\author{
Ulysses Pinheiro ${ }^{1}$ \\ ulyssespinheiro@gmail.com \\ Universidade Federal do Rio de Janeiro, Rio de Janeiro, Brasil
}

resumo 0 presente artigo examina o modo como Leibniz figurou as relações entre o pensamento filosófico e o pensamento místico, recorrendo para isso ao contraste entre suas teses e as de Spinoza. Trata-se de mostrar que a transcendência do fundamento da racionalidade levará Leibniz, de forma à primeira vista surpreendente, a uma valorização da totalidade do campo imanente da experiência humana como fonte de conhecimento. 0 erro do spinozismo, segundo Leibniz, consiste justamente em, ao tornar imanente o fundamento, perder de vista a especificidade cognitiva e ética da experiência.

palavras-chave Leibniz; Spinoza; misticismo; racionalidade; experiência; transcendência

"Spinosa incipit ubi Cartesius desinit: in naturalismo" (LEIBNIZ, 1854, p. $48)$.

\section{Introdução}

A presença constante, abundantemente registrada durante toda a longa carreira intelectual de Leibniz, de uma reflexão sobre o misticismo está muito longe de se reduzir apenas à denúncia dos exageros da imaginação dos "entusiastas", desempenhando antes um papel formador de seu próprio pensamento, especialmente quando ele se volta sobre a natureza da própria racionalidade. Esse papel formador fica particularmente claro no modo como Leibniz traça os limites entre o campo filosófico e o místico. 
A epígrafe acima, retirada de suas anotações feitas por ocasião da leitura de um livro sobre Spinoza e a Cabala (WACHTER, 1706), ao apontar para o principal erro dos "inovadores" em filosofia, mostra que eles padecem de um duplo equívoco: eles erram ao adotar uma teoria falsa sobre a realidade (o naturalismo, que implica o determinismo universal), a qual é apenas uma consequência da concepção, ela mesma naturalista, que tinham da razão. É certo que essa consequência falsa e nociva - a de que "a matéria toma sucessivamente todas as formas" (LEIBNIZ, 1854, p. 48), isto é, que todos os possíveis se realizarão - é apenas "insinuada” por Descartes ${ }^{2}$, só tendo sido levada até suas últimas consequências por Spinoza. Mas o germe do erro é cartesiano: por não ter uma concepção suficientemente complexa da racionalidade, Descartes estava também condenado a, usando a razão, chegar a teses que estavam contaminadas pelo mesmo erro original. Forma e conteúdo, nesse caso, estavam duplamente implicados.

A concepção leibniziana sobre a natureza do discurso filosófico foi formulada, portanto, nessas anotações, a partir de uma oposição à concepção spinozana de filosofia. Ao contrário dos limites nítidos traçados por Spinoza - nesse ponto, um cartesiano, como sublinha frequentemente Leibniz - entre o racional (a filosofia) e o imaginativo (as opiniões), o projeto leibniziano de distinção entre esses dois domínios não pode ser descrito sem se levar em consideração que há também uma continuidade fundamental entre eles. Dessa forma, a caracterização do que significa a natureza do conhecimento racional faz com que, para Leibniz, o que está "fora" do discurso filosófico - o que não é ainda ou não é mais filosofia deva poder ser representado enquanto tal do interior mesmo do sistema filosófico, preservando as condições de verdade próprias a cada um deles. Ou seja, tal representação não se limita, como ocorre na teoria de Spinoza, a preservar e a reconstituir o significado desse sistema "obscuro e confuso" de signos "segundo uma ordem para o intelecto", reservando a avaliação de sua verdade ou falsidade para a esfera da razão pura, mas restitui também a verdade do místico - ou melhor, essa representação racional do irracional mostra de que modo a verdade (que é única) se expressa ai ${ }^{3}$. Dito ainda de outra forma: a experiência mística é irredutível a outros tipos de experiência (à imaginação, como no caso de Spinoza), a partir das quais seria explicada racionalmente; todas as explicações racionais do místico devem partir do reconhecimento de sua especificidade. A descoberta da 
verdade no interior dos domínios do que escapa à racionalidade faz parte essencial, para Leibniz, de sua concepção bastante particular da tarefa de traçar os "limites da razão" - e, novamente aqui, o contraste com a noção cartesiana de "limite"4 é o modelo a ser projetado sobre o spinozismo. Se a figura de Spinoza é particularmente importante sob esse aspecto, é porque, na medida em que representa uma radicalização da posição cartesiana, desempenha simultaneamente uma tendência a ser perseguida e um exagero a ser evitado. De fato, a racionalidade deve ir tão longe quanto possível, reconhecendo-se mesmo ali onde, aparantemente, estamos em presença do irracional; no entanto, a racionalização crescente da experiência humana - que, segundo Ernest Cassirer, é uma das principais marcas do Iluminismo nascente ${ }^{5}$ (CASSIRER, 1992, pp. 32; 47; 52) - deve, ao mesmo tempo, estar atenta para as distorções e ilusões dessa mesma experiência. Acima de tudo, Spinoza se apresenta, aos olhos de Leibniz, como o sintoma de uma hybris filosófica que, ao tentar legislar sobre a totalidade do real, ao mesmo tempo reduziu, por isso mesmo, mas paradoxalmente, o alcance da própria racionalidade.

Mas a concepção leibniziana acerca da racionalidade humana revela-se não apenas em sua tarefa de traçar os limites do conhecimento claro e distinto, mas também em sua caracterização dos fundamentos da razão. Segundo essa última, não podemos encontrar, no interior do mundo conhecido e no mero exame de nossas faculdades de conhecer, o fundamento de sua própria verdade e certeza. Há, na tarefa de fundamentar o conhecimento, uma dupla exigência a ser satisfeita, herdeira do projeto cartesiano de fundamentação metafísica do conhecimento - muito embora Leibniz não aceite a legitimidade do questionamento cético que se encontra na origem do projeto fundacionista cartesiano ${ }^{6}$. Primeiramente, a natureza da razão é tal que ela deve poder chegar a seus próprios fundamentos por meios puramente racionais, sem o que ela passaria a depender de uma determinação heterônoma que introduziria, entre seus primeiros princípios e suas almejadas conclusões, uma distância que não poderia ser percorrida por nenhum encadeamento necessário de ideias. Em segundo lugar, esse fundamento não pode ser dado apenas por um exame do uso imanente das regras racionais, o que faria de todo projeto de fundamentação um raciocínio circular. É a existência de Deus, provada racionalmente, que fundamenta a racionalidade humana; é Sua existência 
que funda a necessidade das conexões entre o sujeito e o predicado de uma proposição condicional (i.e., de uma proposição que é verdadeira independentemente da existência do sujeito do qual é predicada uma propriedade qualquer). A realidade dessa conexão encontra-se, explica Leibniz nos Novos ensaios, na "ligação entre as ideias": considerando a possibilidade lógica de que nenhum espírito existisse, diz ele, isso "nos conduz enfim ao fundamento último das verdades, a saber, a esse espírito supremo e universal que não pode deixar de existir, cujo entendimento, para dizer a verdade, é a região das verdades eternas" (GV, 429) ${ }^{7}$.

Será, portanto, em torno da concepção de racionalidade, de seus limites e de seu fundamento que, veremos, o pensamento sobre o místico desempenhará um papel constitutivo, para Leibniz, de sua própria filosofia. De sua posição frente ao misticismo, veremos também, segue-se uma característica notável de sua atitude em relação às ideias obscuras e confusas em geral. De fato, a transcendência do fundamento da racionalidade o levará, de forma à primeira vista surpreendente, a uma valorização da totalidade do campo imanente da experiência humana como fonte de conhecimento. $\mathrm{O}$ erro do spinozismo, segundo Leibniz, consiste justamente em, ao tornar imanente o fundamento, perder de vista a especificidade cognitiva e ética da experiência.Vejamos como Leibniz articula essa crítica e denuncia esse erro.

\section{A transcendência do fundamento e a verdade da experiência}

As doutrinas místicas são objeto de uma recusa matizada ou de uma aceitação reservada por parte de Leibniz. Mas qual é exatamente a natureza dessa crítica e dessa aceitação parciais ao misticismo, visíveis claramente em textos leibnizianos mais tardios, e já presente de forma mais ou menos explícita desde cedo em seu horizonte teórico? Aludimos acima a uma concepção metafilosófica de Leibniz a respeito da natureza da filosofia, do alcance de suas demonstrações e da maneira como ela lida com fenômenos que lhe são, a princípio, estrangeiros. É preciso especificar melhor essa hipótese explicativa.

Donald Rutherford nota (RUTHERFORD, 1998, p. 22) que "as observações dispersas de Leibniz sobre o misticismo estão perpassadas por 
um tema recorrente: há algo correto no que os místicos dizem, mas isso é expresso de maneira errada ou confusa" ${ }^{8}$. Rutherford acredita - corretamente, a meu ver - que essa atitude constante de Leibniz frente aos místicos indica algo mais do que uma simples profissão de fé sobre a tolerância religiosa e a liberdade de expressão. Para Rutherford, o que essa atitude sinaliza é o elogio de Leibniz à capacidade do discurso místico de despertar a piedade em seus ouvintes e leitores (de modo similar, eu acrescentaria, ao elogio que Spinoza faz à "verdadeira religião", adequada à "mente do vulgo"). Há, entretanto, eu creio, um motivo mais profundamente enraizado na própria filosofia leibniziana para justificar seu interesse contínuo pelo misticismo - um motivo que faz do misticismo um objeto necessário de sua consideração atenta. Normalmente, a estratégia adotada pelos comentadores ${ }^{9}$ para explicar o interesse de Leibniz em relação ao misticismo leva em conta a gênese de algumas de suas ideias filosóficas a partir das teses de certos místicos, sem deixar de enfatizar a disposição leibniziana de construir, a partir dessas influências, uma filosofia racional, rigorosa e dedutiva, disposição essa incompatível com a confusão e vagueza metafórica dos discursos místicos. Isso certamente é (parte da) verdade, mas não é suficiente. É preciso entender, além disso, que as diversas "correções" racionais que Leibniz propõe para certas teses místicas não podem ser plenamente compreendidas apenas através da elucidação do modo como cada uma delas em particular pretende eliminar sua obscuridade e as conduzir a suas formulações mais adequadas. Para dar um exemplo, não basta entender o modo como a tese da alma do mundo é criticada e substituída pelo pan-psiquismo das mônadas (i.e., como Leibniz prova, a partir da divisão ao infinito da matéria, que cada porção sua contém criaturas vivas $\left(\mathrm{GVI}, 618^{10}\right)$ ). Tais correções particulares são, na verdade, apenas a manifestação aparente de uma posição mais fundamental a respeito da natureza do conhecimento racional. Essa posição mais fundamental deriva do esforço próprio da filosofia leibniziana, de sua essência mesma (se aceitarmos a identificação spinozista entre conatus e essência atual), para expressar racionalmente o que, à primeira vista, é opaco à razão, devido a uma certa concepção sobre a natureza da racionalidade. Além disso, não se pode entender a recusa da posição mística apenas pelo fato de ela ser composta por ideias obscuras e confusas - pois esse entendimento eliminaria o tipo específico de confusão cometido pelos místicos do horizonte de investigação, 
assimilando-o às confusões cometidas ordinariamente por desatenção, preguiça ou ignorância. O que o místico quer dizer tem algo de verdadeiro, repete Leibniz insistentemente, apenas ele não o formula corretamente o que demanda uma formulação alternativa e precisa. Em outras palavras, há um conteúdo particular, dado apenas pela experiência mística, que deve ser resgatado. Finalmente, não é possível tampouco explicar a atitude de Leibniz frente ao discurso místico como sendo uma consequência de sua "posição biográfica" particular - por exemplo, como o resultado de sua adesão a uma forma mais ortodoxa de cristianismo. De fato, é muito comum ler, nos comentadores de Leibniz, a interpretação de que ele recusa tal ou tal doutrina mística devido a suas teses teológicas ou morais, o que nos leva apenas a um exame míope de argumentos dirigidos contra cada tese mística em particular. Ao contrário, proponho que os dados biográficos e as teses particulares encontram sua matriz de inteligibilidade em um elemento estrutural ${ }^{11}$. Sendo assim, a recusa matizada ao misticismo não deve mais ser vista como o mero efeito cumulativo de posições particulares assumidas por Leibniz (o que explicaria a "superficialidade" de que ele é frequentemente acusado, na medida em que se limitaria a justapor suas posições, já tomadas como verdadeiras, às teses a serem refutadas), mas, antes, como um fim em si mesmo. É preciso ler, nos seus textos sobre o misticismo, uma questão latente que os perpassa a todos, um problema a ser formulado e resolvido. Se o misticismo sempre ocupou o interesse de Leibniz, isso não se deve apenas a sua insaciável curiosidade natural, mas antes à questão mais fundamental que ela expressava tacitamente: é a recusa de um fundamento intramundano da razão que explica a obsessão de Leibniz com as teses místicas. O misticismo não é, portanto, apenas mais um objeto dentre outros a ser examinado pela curiosidade do polimata, mas exprime, como veremos a seguir, um elemento estrutural do pensamento de Leibniz, o qual subordina, sob seu escopo, todas as objeções a teses místicas particulares.

Fruto de uma espécie de emanação ou de fulguração (G VI, 614 $4^{12}$ ) de Deus, o mundo criado exprime, em todos os seus mínimos detalhes, a essência divina. Tudo é uma questão de graus, há um contínuo entre razão e experiência, de tal modo que a tarefa da razão é procurar expandir permanentemente seus domínios sobre o que aparece, para nós, como obscuro e confuso, mas que é, em si mesmo e de direito, claro e distinto. 
Daí as "hesitações" de Leibniz frente ao discurso místico: além de uma legítima dúvida intelectual sobre quais (se é que alguma) de suas teses poderiam ser incorporadas a um sistema filosófico racional, tal hesitação indica também a busca de um maximum de racionalidade terrena, a qual, entretanto, não poderia ir tão longe quanto o spinozismo, uma vez que esse último restringe a razão ao próprio mundo, eliminando, assim, a transcendência do fundamento. Essa tensão ineliminável do leibnizianismo poderia ser formulada, correndo os riscos de uma generalização simplificadora, como a convivência, em sua obra, de um impulso pré-Iluminista que reconhece, na imanência do mundo, seu próprio fundamento (e, para um certo Iluminismo, tal imanência vai se traduzir em termos de uma mecânica puramente materialista) e de uma reação contra-Iluminista avant la lettre que estabelece, em uma realidade transcendente, o lugar de um fundamento racional que só poderia ter as características de ser absoluto - o infinito em ato $^{13}$ - e puramente espiritual. (Como se sabe, o Idealismo e o Romantismo alemães caracterizam-se por uma retomada de Spinoza contra, simultaneamente, o Iluminismo e o dogmatismo metafisico - e, nesse sentido, contra duas vertentes presentes, segundo seus representantes, na filosofia de Leibniz. Que Spinoza tenha, ao longo dos séculos XVIII e XIX, servido como referência tanto para os Iluministas "radicais" ${ }^{14}$ quanto para o anti-Iluminismo alemão apenas mostra o quanto uma tensão semelhante à de Leibniz também atravessava seus textos).É no cálculo para manter a balança entre essas duas tendências que devemos ler positivamente as "hesitações" de Leibniz frente ao místico, ao invés de reduzi-las a um traço meramente psicológico de sua personalidade ou a um dado histórico de sua evolução intelectual.

As diferenças entre Leibniz e Spinoza relativamente à concepção do fundamento da investigação racional encontra aqui, na maneira como cada um deles assimila as experiências opacas à razão ao campo da racionalidade, seu ponto mais visível. Limitemo-nos, por ora, a estabelecer esse contraste no que diz respeito às experiências sensíveis, deixando o exame das experiências místicas para mais adiante ${ }^{15}$.

2.1 As relações entre o conhecimento racional e a experiência sensível 
Tanto Spinoza quanto Leibniz criticaram a proposta metafísica e metodológica cartesiana de recusar qualquer valor cognitivo às sensações para além da mera função denotativa de "indicar" a existência de $\operatorname{corpos}^{16}$. Ambos, entretanto, lidam de forma diferente com relação à natureza da contribuição cognitiva e ética da experiência sensível para o aperfeiçoamento humano. A tese de que a verdade se encontra em toda parte, de modo mais ou menos desenvolvido, é um elemento essencial para a análise leibniziana do conhecimento sensível. De fato, dado o reconhecimento de que a mente contém sempre em si uma infinidade de "pequenas percepções insensíveis", desacompanhadas de apercepção e de reflexão $(\mathrm{G} \mathrm{V}, 41-62)^{17}$, as quais, quando afetam conjuntamente a consciência, se manifestam como percepções obscuras da sensação, é possível explicar a verdade do domínio sensível tomando como base a continuidade essencial entre ele e o domínio raciona $1^{18}$. As ideias da sensação, nelas mesmas, são tão claras e distintas quanto as ideias da razão, mas, devido ao fato de serem "muito pequenas e em muito grande número ou muito unidas" (GV, 46) $)^{19}$, só são percebidas pelas mentes finitas de modo obscuro, como um todo cujas partes não são apreendidas por si mesmas. Há, portanto, uma identidade qualitativa, e uma mera distinção de graus, entre todas as ideias, o que garante, por princípio ao menos, a inteligibilidade completa dos dois domínios, o racional e o sensível ${ }^{20}$.

Já para Spinoza, o "conhecimento do primeiro gênero", que tem origem nas sensações, é necessariamente inadequado, sendo, mais do que isso, a única causa da falsidade (Ética, II, p. 41). É verdade que a teoria spinozana do conhecimento afirma que a experiência sensível é uma condição necessária para o despertar das ideias adequadas do segundo e do terceiro gêneros (Cf. MATHERON, 2011), mas ela não pode ser nunca a causa das ideias adequadas da razão (Ética, II, p. 36), sendo apenas sua ocasião. Assim, enquanto, para Leibniz, não podemos duvidar da verdade própria das sensações, já que - malgré Descartes - elas são dotadas de uma "certeza luminosa" no seu gênero - i.e., relativamente à nossa prática (G V, 424$429)^{21}$-, para Spinoza a rejeição da dúvida cartesiana baseia-se na auto-evidência das percepções racionais (Ética, II, p. 48 e p. 49), sendo legítima, no entanto, senão uma dúvida universal sobre os sentidos, pelo menos a doutrina cartesiana segundo a qual as sensações são sempre sistematicamente enganosas ${ }^{22}$. 
Parecem poder ser derivadas, portanto, dessa contraposição entre as teses de Leibniz às de Spinoza sobre a distinção entre a razão e a sensação duas relações simetricamente opostas presentes em cada uma das duas teorias: para Leibniz, a transcendência do fundamento cognitivo implica que nossas representações sensíveis são intrinsecamente verdadeiras ${ }^{23}$; para Spinoza, a imanência do fundamento (i.e., o abandono da ideia mesma de criação) implica que, embora o mundo seja inteiramente racional, nosso conhecimento sensível dele não contém em si mesmo nenhuma verdade intrínseca. Ou seja, enquanto a filosofia leibniziana, ainda que guardando a grande diferença entre nossas duas faculdades de conhecer, estabelece uma continuidade fundamental entre razão e sensação, a filosofia spinozana demonstra haver entre elas um abismo intransponível ${ }^{24}$. Essa contraposição entre os dois sistemas não deixa inteiramente claro, porém, o significado da implicação entre seus termos. A pergunta que deve ser respondida, portanto, é a seguinte: o que significa precisamente a relação entre a transcendência (ou a imanência) do fundamento e a distinção entre razão e sensação?

Mais do que no exame das relações entre racionalidade e experiência sensível, porém, será no modo como o campo da razão se distingue e se integra com o da experiência mística que a função dos diversos tipos de fundamento (imanente ou transcendente) poderá ser esclarecida de modo mais direto. Isso não é surpreendente, já que, ao contrário do que ocorre com a experiência sensível, o objeto mesmo da experiência mística é o fundamento de todo o conhecimento humano. Vejamos, então, como Leibniz e Spinoza entendem o valor cognitivo da experiência mística.

2.2 As relações entre o conhecimento racional e a experiência mística

Devido ao fato de que tanto nossas deduções racionais quanto nossas experiências (sensíveis ou místicas) pertencerem igualmente ao mundo criado, desempenhando, portanto, no sistema leibniziano, a função de serem o fundado, ou seja, aquilo que não contém em si mesmo seu próprio fundamento (o qual reside em um Deus transcendente), esse mundo da experiência será compreendido por Leibniz como sendo permeado por uma racionalidade intrínseca que não permite estabelecer fronteiras 
nítidas entre o que é capaz e o que não é capaz de exprimir a verdade. Se, retrospectivamente, Descartes mostra, na Sexta Meditação, que os argumentos céticos aceitos no contexto cognitivo da Primeira Meditação dependiam do "antigo hábito" de tomar as sensações como fonte legítima e primária de conhecimento, para Leibniz, ao contrário, a recusa preliminar da legitimidade do ceticismo vem acompanhada do reconhecimento do valor cognitivo - embora não primário - das sensações. Portanto, o conhecimento obscuro e confuso - das sensações, por exemplo, mas também o envolvido pelo acesso místico à divindade -, por ser parte do mundo criado, deve também ele conter, intrinsecamente, as marcas da verdade e da certeza, bastando, para perceber isso, que saibamos decifrar em signos o modo como ele se expressa em uma outra linguagem, a língua da razão pura, traduzindo-o em termos claros e distintos. Veremos mais adiante em que consiste essa tarefa de tradução; por ora, basta assinalar sua finalidade geral.

A adoção de uma concepção do fundamento como se situando em um nível transcendente explica, portanto, por que o campo imanente da experiência foi pensado por Leibniz como sendo uma expressão particular da verdade. Porque Spinoza não viu isso, sugere Leibniz, é a razão pela qual sua teoria foi incapaz de perceber a verdade do misticismo (a verdade do que o místico quis dizer) e, ao mesmo tempo, a razão pela qual ela mesma sucumbiu a uma forma velada de misticismo. Esse também é o motivo, diz Leibniz, da "divertida" [plaisante] tese metafísica ${ }^{25}$ enunciada na parte V da Ética, segundo a qual a "parte eterna" de nossa mente, que subsiste à destruição do corpo, é um ente impessoal e puramente racional. Ora, repete sempre Leibniz, é impossível pensar no conceito de uma alma sem unir a ela sensações e memórias.

A comparação do modo diverso como Leibniz e Spinoza "integram" a experiência mística no contexto do discurso racional explicará, como veremos a seguir, a necessidade de Leibniz figurar o spinozismo, ao mesmo tempo, como uma redução indevida do misticismo à mera dimensão psicológica e sociológica do homem e como sendo, paradoxalmente, ele mesmo uma capitulação involuntária ao misticismo.

De fato, para Spinoza, o fundamento do conhecimento racional é imanente ao mundo. Quer se trate da substância absolutamente infinita, quer se trate das "mediações" entre o absolutamente infinito e o finito (os 
modos infinitos imediatos e mediatos dos atributos de Deus), o mundo contém intrinsecamente sua própria razão de ser. Tudo o que, no conhecimento racional, não for perfeitamente claro e distinto deve ser visto como sua alteridade absoluta (a imaginação, a religião e o místico).A lógica imanente desses domínios que se situam "fora" da razão, propõe Spinoza, deve ser preservada (SPINOZA, 2008, p. 36), sem se pretender "racionalizar" tais experiências a partir de uma regra de encadeamento que não é a sua (ao contrário, por exemplo, do que faziam aqueles que, como Maimônides, tentam dar uma interpretação alegórica das Escrituras Sagradas a partir da suposição de que elas transmitem teses racionalmente demonstráveis ${ }^{26}$ ). Mas a "lógica da imaginação" só pode ser formulada, para Spinoza, pela razão. Ou seja, é ao discurso racional que compete descrever, interpretar e dizer, a partir de um método forjado especialmente para isso, a verdade da imaginação, mantendo-a, entretanto, como um domínio essencialmente irracional. Ao mesmo tempo que essa atitude em relação ao fenômeno religioso/imaginativo elimina desse último qualquer valor cognitivo, ela mantém sua alteridade radical à vista. Vejamos, pois, em que consiste a "tradução" spinozana da imaginação religiosa pela razão.

\subsection{1- Conhecimento racional e experiência mística em Spinoza}

Seria natural esperar que o texto paradigmático a ser examinado neste momento, tendo em vista o estabelecimento das relações entre o conhecimento racional e a experiência mística em Spinoza, fosse a parte V da Ética, na qual as noções de contemplação intuitiva, união com Deus, experiência da eternidade e beatitude ocupam o centro das demonstrações $^{27}$. Deve-se notar, porém, que o próprio Spinoza não julgava que se tratava aí de uma doutrina mística; ao contrário, era essencial ao projeto da Ética que a parteV fosse dedutivamente encadeada ao resto do livro - ou melhor, que ela fosse intuitivamente percebida em sua ligação racionalmente necessária com ele. Ao afirmar que o conhecimento intuitivo é o responsável pelo estabelecimento da verdade das proposições da parte $\mathrm{V}$, devemos nos recordar que a intuição é definida, no escólio da proposição 40 da segunda parte da Ética, como o gênero de conhecimento que "procede [procedit] do conhecimento adequado da essência formal de certos atributos de Deus para $[a d]$ o conhecimento adequado da essência das coisas". Ou seja, a intuição é, para Spinoza, como para Descartes, um 
processo ou um movimento racional, através do qual a ideia da essência do homem é pensada em sua união com Deus.

O lugar sistemático da tematização da experiência mística no interior da filosofia spinozana não é, portanto, a parteV da Ética.Vamos encontrá-lo, ao invés disso, nos primeiros capítulos do Tratado teológico-político, nos quais Spinoza investiga a experiência mística sob a figura do profeta e de suas crenças. Deve-se notar que, nessa obra, Spinoza não só propõe uma analogia entre experiência sensível (ou melhor, imaginativa) e experiência mística, mas as identifica. Assim, no capítulo II, ao analisar a "certeza profética" [certitudo prophetica] (G III, 17), seu primeiro cuidado é o de distingui-la da "certeza matemática" [certitudo mathematica], exclusiva das ideias claras e distintas da razão. Isso não quer dizer, porém, ele nos adverte, que a experiência dos profetas não fosse dotada de uma "certeza moral" [certitudo moralis] com alto grau de confiabilidade - ao contrário, diz Spinoza, elas continham em si "muita certeza" [multum certitudinis]. Mas as experiências místicas dos profetas não eram dotadas da certeza racional, a qual contém em si mesma o índice de sua verdade; a certeza profética, ao contrário, se baseava em três elementos extrínsecos: " 1 - os profetas imaginavam as coisas reveladas com muita vivacidade [vividissime], tal como o fazemos quando estamos no estado de vigília, afetados pelos objetos; 2- um signo; 3- enfim, e sobretudo, eles tinham uma alma inclinada somente ao justo e ao bom" (G III, 17). Pela condição 1, Spinoza assimila a experiência profética à imaginação - ainda que se trate de um tipo peculiar de imaginação, dotada de alto grau de força e vivacidade, tal como aquele presente nas percepções sensíveis. Pela condição 2, ele mostra que, à certeza intrínseca, característica das ideias claras e distintas da razão, é oposta a certeza extrínseca das ideias imaginativas, as quais requerem uma confirmação suplementar, enviada por Deus, de que o que os profetas perceberam era verdadeiro ${ }^{28}$. Finalmente, pela condição 3, é assegurada a dimensão prática da certeza profética: porque Deus é justo, ele não mente aos justos.

Mas Spinoza não se limita, no Tratado, a descrever, de um ponto de vista externo, as crenças do profeta; ele introduz, paralelamente, uma avaliação da confiabilidade dessas crenças do ponto de vista da "verdadeira religião". Será o exame dessa avaliação que nos permitirá entender como a noção de fundamentação do conhecimento determina o modo como 
Spinoza entende os limites da razão, particularmente no que diz respeito ao conhecimento imaginativo.

Os capítulos iniciais do Teológico-político examinam os dogmas da "verdadeira religião" - i.e., "verdadeira" para a filosofia do próprio Spinoza - a partir de um duplo ponto de vista, sintetizado, porém, na unidade superior de um de seus pólos constitutivos: por um lado, trata-se de descrever o funcionamento da imaginação profética em seu registro próprio; por outro lado, trata-se de demonstrar, do ponto de vista absoluto da razão, que a imaginação revela doutrinas importantes relacionadas à "verdadeira religião", coincidentes com as mesmas doutrinas sobre a salvação que o filósofo é capaz de demonstrar racionalmente. Isso permite que Spinoza conclua que, deixando as narrativas originadas da imaginação profética tal como elas são descritas na Bíblia, sem pretender "corrigi-las" pela razão (ou seja, sem lançar mão de leituras alegóricas do texto bíblico, como Maimônides o fez), podemos atribuir ao conhecimento imaginativo um núcleo comum partilhado com o conhecimento racional, a saber: o enunciado das leis morais. Mas o ponto de vista da razão faz mais do que descobrir coincidências entre doutrinas racionais e imaginativas: ela sintetiza, em sua unidade explicativa, não só os conteúdos demonstrados, mas também as formas de demonstração, tanto da própria razão quanto da imaginação. Ou seja, trata-se não só de mostrar que certas proposições da Bíblia, cujos sentidos literais foram estabelecidos pelo método hermenêutico criado por Spinoza, são verdadeiras (o que só pode ser feito por meio de demonstrações racionais, e não na medida em que permanecemos no campo imaginativo ${ }^{29}$ ), mas, além disso, de explicar racionalmente a lógica própria da imaginação na produção da imaginação profética e da fé em seus relatos, incluindo aí uma explicação das eventuais distorções imaginativas que levam os fiéis a uma deriva em direção à superstição. Finalmente, a razão deve explicar o modo como ela mesma integra esses sentidos literais, comuns à fé e à filosofia, ao ponto de vista racional, de tal maneira que o sentido mínimo coincidente com a imaginação ganhe um sentido mais amplo compatível com a filosofia verdadeira, isto é, com o spinozismo.

Essa duplicidade de pontos de vista, sintetizados no que diz respeito aos conteúdos comuns visados pelas dinâmicas produtivas divergentes da imaginação e da razão, gera, necessariamente, uma duplicidade nas 


\section{4}

estratégias argumentativas e textuais do Tratado; é preciso ler suas análises do texto bíblico, e particularmente, no caso que nos interessa aqui, suas explicações da experiência profética, sob um duplo registro: 1- o que distingue absolutamente a imaginação da razão, respeitando a lógica própria da primeira, mas, simultaneamente, 2- o da razão incidindo sobre o modo de produção da imaginação e da própria razão, mostrando como a coincidência de conteúdos literais mínimos é compatível com a existência de contextos interpretativos mais amplos e distintos que os integram (sendo que a imaginação, nesse caso, é subordinada à razão, pois é essa última que a explica, do ponto de vista naturalista de uma psicologia racional). De fato, no capítulo VII do Tratado, Spinoza afirma que o método de interpretação a ser usado na leitura da Bíblia é o mesmo que o usado na interpretação da natureza: é preciso partir de definições, que não são dadas diretamente nem na natureza, nem no texto bíblico, para daí poder articular o sentido daquilo que é dado e, em seguida, avaliar sua verdade. É importante notar, nesse contexto, que os capítulos iniciais do Tratado sempre começam por definições reais e verdadeiras (de "profecia", "profeta", "lei natural", "providência externa de Deus", etc.), de tal modo que a linguagem bíblica possa ser, a partir delas, compreendida adequadamente. Para Spinoza, a salvação do vulgo (entendamos bem: do homem comum ocidental do século XVII, educado na religião cristã, e não de todo e qualquer homem, vivendo em qualquer cultura e em qualquer tempo) depende da leitura maximamente literal do texto bíblico. Tendo em vista a maximização da literalidade do texto bíblico, a operação de leitura proposta por Spinoza é sutil: por um lado, trata-se de deixar a imaginação funcionar segundo suas regras próprias, sem propor uma leitura alegórica do texto a partir de teorias filosóficas particulares, o que, de forma aparentemente paradoxal, só pode ser feito, porém, se a lógica imaginativa for descrita a partir da única teoria filosófica verdadeira, a spinozana; por outro lado, trata-se de criticar as interpretações equivocadas oriundas do próprio conhecimento imaginativo, também elas causas de distorções em relação a uma leitura literal (por exemplo, a concepção do milagre como o índice mais certo da existência de Deus ${ }^{30}$ ), usando como critério de verdade a teoria metafísica spinozana. Dupla operação, portanto: restituir o sentido literal do texto, usando para isso o conhecimento racional (a saber, estudos filológicos e históricos), mas, ao mesmo tempo, manter a 
interpretação do texto a partir da imaginação, mostrando que apenas essa leitura maximamente literal preserva a lógica própria do conhecimento imaginativo. O objetivo de Spinoza, com essa dupla operação de leitura, é mostrar racionalmente que o conhecimento imaginativo dos profetas concorda, pelo menos em um núcleo central, com os ensinamentos da verdadeira lei divina apreendida pelo intelecto puro - a prática moral da virtude e da caridade, o amor a Deus, a justiça ${ }^{31}$. Mas há um outro objetivo, que sintetiza os conteúdos imaginativos em um nível superior: trata-se da explicação, por uma teoria racional da imaginação, dos meios imaginativos pelos quais essa verdade foi revelada, bem como do modo como ela deve ser entendida no contexto da verdadeira filosofia. Ou seja, é possível provar, para aqueles que examinam o texto bíblico usando a razão, que o profeta, usando a imaginação, pode chegar às mesmas verdades que o filósofo, embora tal demonstração não seja acessível ao próprio profeta.

A partir do que foi dito até aqui, o contraste da interpretação spinozana das Escrituras Sagradas com a atitude de Leibniz diante dos limites da razão frente ao místico fica evidente. No horizonte desse contraste, está a leitura leibniziana segundo a qual Spinoza, ao resignificar as experiências místicas dos profetas no interior de seu próprio sistema, seguindo as orientações de um naturalismo radical, não podia, por isso mesmo, reconhecer qualquer verdade manifestada intrinsecamente no nível dessas próprias experiências. Entendamos bem: também para Leibniz, embora "o que o místico diz" seja essencialmente verdadeiro, o modo como ele o diz é obscuro e confuso, sendo preciso traduzir seu discurso a partir de um ponto de vista racional ${ }^{32}$. Ao contrário de Spinoza, porém, para Leibniz tal "tradução" deixa intacto o conteúdo atribuído pelos místicos a suas experiências: porque essas últimas são, em última análise, verdadeiras (na mesma medida em que as sensações, obscuras e confusas para nós, são, de direito e em si mesmas, claras e distintas), a regra que rege a tradução muda completamente. Não se trata mais de atribuir à experiência mística uma leitura de moldes naturalistas, mas antes de preservar nela sua perspectiva própria acerca da verdade. Será justamente porque não soube fazer isso, dirá Leibniz, que Spinoza, pretendendo reduzir o místico ao imaginativo, acabou, paradoxalmente, não reconhecendo o quanto sua própria teoria contém de um misticismo fundamentalmente supersticioso e ilusório. Em suma: incapaz de reconhecer o verdadeiro misticismo, Spinoza não teria 
sabido afastar o falso, quando influenciado por ele. Vejamos, a seguir, os detalhes dessa crítica.

\subsection{2- Conhecimento racional e experiência mística em Leibniz}

Vimos acima que, no Elucidador cabalístico, Wachter, ao advogar por uma espécie de cabala cristianizada, defende a influência do misticismo cabalista sobre (bem como sua compatibilidade com) a filosofia de Spinoza. O comentário de Leibniz ao livro de Wachter, que se encontra na biblioteca de Hanover sob o título Anotações críticas sobre o livro de J. G. Wachter a respeito da filosofia secreta dos judeus (Animadversiones ad J. G. Wachteri librum de recondita Hebraeorum philosophia), foi descoberto e publicado por Foucher de Careil no século XIX ${ }^{33}$. Embora Wachter não tenha compreendido de modo inteiramente correto a filosofia spinozana, o que foi notado algumas vezes por Leibniz em suas anotações, esse último parece ter tido seu interesse despertado sobretudo pelas possibilidades que a aproximação entre o spinozismo e a Cabala, proposta por Wachter, teriam aberto. Em linhas gerais, Wachter tenta mostrar que tanto Spinoza quanto a Cabala são incompatíveis com a doutrina da alma do mundo, na medida em que ambos rejeitam interpretar a relação entre Deus e o mundo a partir da analogia entre a mente e o corpo humanos. Para Wachter, Spinoza e a Cabala propõem, ao contrário, que Deus é o Espírito do mundo, a partir do qual a matéria (que não é dotada de realidade por si mesma, sendo apenas uma mera manifestação fenomênica do Espírito) deriva por emanação $^{34}$. Como Leibniz escreve suas anotações privadas seguindo a ordem dos capítulos do livro de Wachter, é no momento em que ele comenta seu capítulo central (o capítulo 4, intitulado "De consensu Cabalae et Spinozae") que a assimilação do spinozismo ao misticismo é mais enfatizada. Curiosamente, Leibniz assimila, nesse momento, e contra as advertências de Wachter, o spinozismo à doutrina da alma do mundo, embora, em escritos anteriores, ele os tenha separado ou pelo menos, nuançado tal identificação. Diz ele aí: “em seu discurso aos gregos, Taciano diz que um espírito preenche as estrelas, os anjos, as plantas, as águas, os seres humanos, os animais e que, embora ele seja um e o mesmo, ainda assim exibe diferenças” (LEIBNIZ, 1848, p. 45). Mas, continua Leibniz, "eu rejeito essa doutrina", identificando-a em seguida ao spinozismo. Ora, é justamente esse o ponto central de sua crítica a Spinoza nessa época: ao adotar a tese 
da alma do mundo, o spinozismo torna o fundamento da racionalidade imanente ao próprio mundo. Dado esse naturalismo radical, toda experiência mística deveria ser então traduzida em termos imaginativos, na medida em se aceite que esses últimos esgotam a totalidade da experiência possível neste mundo.

Para Leibniz, ao contrário, como vimos acima, a transcendência do fundamento implica que tanto nossas deduções racionais quanto nossas experiências sensíveis ou místicas pertençam todas indiferentemente ao mundo criado, o que faz com que todas elas sejam compreendidas por Leibniz como sendo permeadas por uma racionalidade intrínseca que não permite estabelecer fronteiras nítidas entre o que é capaz e o que não é capaz de exprimir a verdade ${ }^{35}$. Ou seja, é pelo mapeamento de uma espécie de arquitetônica do conhecimento, na qual o fundamento da cognição é localizado a igual distância de todas as formas de conhecimento e de experiência humanos, que Leibniz pode reconhecer uma igual capacidade de todas as nossas faculdades de apreender o mundo expressarem a verdade. Essa metáfora arquitetônico-espacial pode ser reformulada nos seguintes termos: se um Deus transcendente é o fundamento de todo o nosso conhecimento, e se a relação desse Deus com o que Ele causa (i.e., a totalidade de nossa experiência do e no mundo - na medida em que ela faz parte do próprio mundo) é tal que Ele provê não apenas a explicação para a eternidade das verdades necessárias, mas também a razão suficiente para todas as verdades contingentes, então é necessário concluir que não pode haver nada no domínio do que pode ser experimentado que não exprima, ainda que de modo necessariamente obscuro, alguma verdade. Já o fundamento spinozano (o intelecto infinito de Deus) restringe a verdade apenas às ideias racionais ou intuitivas, justamente por causa de sua imanência: a experiência sensível é necessariamente mutilada e confusa e, embora possa ser explicada pela razão, não contém, nela mesma, nenhuma verdade. A razão humana é uma parte do intelecto de Deus e, como tal, esgota o domínio do que pode ser concebido segundo a verdade; a sensação não é explicada a partir da causalidade divina, como algo de positivo gerado por ela, mas apenas como ausência e negação do ser. Uma ideia falsa é, nesse caso, uma ideia parcial, parcialidade essa que a condena ao domínio do falso.

Poder-se-ia objetar, corretamente aliás, que não foi demonstrado haver uma implicação simples e geral entre a transcendência do fundamento 
e a expressão da verdade em todo o domínio das ideias, quer sejam elas ideias do intelecto puro ou ideias da sensação. De fato, parece, à primeira vista, que encontramos em Descartes, por exemplo ${ }^{36}$, uma contra-prova da generalização de tal implicação: para ele, o fundamento do conhecimento é o Deus transcendente e, ao mesmo tempo, ele nega que as ideias sensíveis exprimam alguma verdade - além das verdades existenciais sobre as coisas corporais que afetam nossos corpos. Mas a contraprova falha, por uma razão simples: não podemos esquecer que o Deus cartesiano criou indiferentemente todas as verdades, tanto as contingentes quanto as necessárias, de tal modo que nada além de sua vontade (não determinada por nada - nem por seu intelecto) é a causa das ideias. Isso significa que, para Descartes, o fundamento não garante que a totalidade das ideias seja verdadeira. Ora, o próprio Spinoza se encarregou, no escólio 2 da proposição 33 da parte I da Ética, de anunciar sua aliança com Descartes no que diz respeito a esse ponto preciso: se tivesse de escolher a tese mais errada, dentre aquela que propõe haver um Deus indiferente a tudo e aquela que afirma que a vontade divina é determinada por Seu intelecto, Spinoza escolheria a primeira opção - ou seja, ficaria ao lado de Descartes. A linha que separa Leibniz de Descartes foi então traçada precisamente por Spinoza: o que esse último não poderia admitir é um Deus que, sendo transcendente ao mundo, ao mesmo tempo fornecesse, a partir de Seu intelecto, uma razão determinada para tudo o que existe. O referido escólio 2 o diz claramente:

Pois esses últimos [a saber, aqueles que sustentam que Deus em tudo age tendo em vista o bem] parecem supor a existência, fora de Deus, de alguma coisa que não depende dele, uma coisa que, ao operar, ele toma como modelo, ou uma coisa a que ele visa como se fosse um alvo preciso [vel ad quod tamquam ad certum scopum collimat]. Mas isso não significa senão submeter Deus ao destino: não se poderia sustentar nada de mais absurdo a respeito de Deus, que é, como mostramos, a causa primeira e única, tanto da essência quanto da existência de todas as coisas. Por isso não perderei tempo refutando tais absurdos ${ }^{37}$.

Leibniz, em suas anotações à Ética, escritas em 1678, já havia comentado essa passagem:"no segundo escólio, nega que Deus em tudo age tendo em vista o bem [sub ratione boni]. Não é de admirar que lhe negue a vontade 
e que afirme que seus oponnentes submetem Deus ao destino, ainda que ele mesmo tenha admitido que Deus em tudo age tendo em vista a perfeição" (G IV, 149). O que está em jogo nessa disputa é, portanto, o significado da "submissão" da vontade de Deus à esfera das essências eternas, o que tem óbvias implicações a respeito da produção das coisas existentes no espaço e no tempo, na medida em que essas últimas são, para Leibniz, possibilidades contidas no intelecto infinito de Deus. Sua solução para esse problema é bem conhecida, e não é necessário nos determos nela aqui. O que cabe notar é somente que, para a concepção spinozana, quando a razão descobre que seu fundamento é a totalidade racional da qual ela é uma parte, é forçoso excluir - através de uma fronteira nitidamente traçada - tudo o que não é racional do domínio do que pode expressar alguma verdade.

Não haveria, porém, um outro contraexemplo que não a filosofia cartesiana para questionar a generalidade da tese que une a transcendência do fundamento à expressão onipresente da verdade em todo o campo da experiência? A resposta é provavelmente afirmativa, mas ela não impede que, pelo menos no contexto que estamos examinando - a posição de Leibniz sobre o misticismo, em contraposição à radicalização do cartesianismo representada por Spinoza -, a tese mantenha sua generalidade restrita.

(Uma observação marginal: é muito comum encontrar, nos comentários à obra de Spinoza, referências à importância da tese da imanência de Deus ao mundo,ou seja, à Natureza, para sua teoria ética: ainda que a inexistência de um Deus transcendente não impeça o conhecimento e a prática das virtudes - sendo, antes, mais propriamente, a sua condição -, o conteúdo das virtudes e a compreensão das ações morais são grandemente modificados pela aceitação da tese da imanência de todas as coisas em Deus.Vimos agora, também, a importância da tese da imanência divina para sua teoria do conhecimento e para sua teoria da verdade. Por contraste, a valorização leibniziana da experiência sensível relativamente à transcendência de um Deus - não-cartesiano, ou seja, não-indiferente torna-se clara).

Para Leibniz, portanto, o fundamento do conhecimento racional é transcendente ao mundo e, justamente por isso, como vimos, o campo da experiência como um todo é pensado como sendo intrinsecamente racional. Das verdades eternas percebidas pela razão aos múltiplos dados 
da sensação, um arco contínuo é traçado porque o campo da experiência é aquilo que é fundado, uma vez que o mundo criado é um todo unificado. Isso faz com que sua atitude diante do discurso místico seja a de procurar "traduzir" todas as suas teses válidas para o domínio da racionalidade, eliminando apenas aquilo que é totalmente opaco à razão. Há uma espécie de positivismo discursivo (o qual não tem nada em comum com os positivismos dos séculos XIX e XX) que garante, por princípio, um estatuto racional para todo o mundo criado. Uma das críticas que Leibniz faz ao “spinozismo místico" de um Wachter, justamente quando esse último relaciona a noção cabalística de "Espírito do mundo" ao conceito spinozano de "modo infinito imediato do Pensamento", é dirigida precisamente contra a concepção spinozista da essência da alma humana, segundo a qual ela seria a ideia eterna do corpo humano existente em ato - uma ideia, portanto, puramente intelectual. Ora, argumenta Leibniz, não há intelecto sem sensação e memória:

Spinoza, na quinta parte Ética, proposição 21, diz que a memória e a imaginação desaparecem [evanescere] com o corpo. Mas creio que sempre permanece algo da imaginação e da memória, e que, sem elas, a alma seria um puro nada. Não se deve acreditar que a mente existe sem o sentimento ou sem uma alma [sensu seu anima]. Uma razão sem imaginação nem memória é uma consequência sem premissas (LEIBNIZ, 1854, p. 58) . $^{38}$.

O tema da imanência do fundamento é ligado assim, por Leibniz, ao tema da natureza puramente intelectual da alma em Spinoza. A crítica a um desses tópicos implica a recusa do outro. O lema "sensu seu anima" e a valorização da experiência que ele implica mostra que essa última tem seu valor cognitivo próprio, desde que sua continuidade essencial com a razão - da qual, aliás, essa última emerge por aumento de graus de clareza e distinção - seja trazida à luz.

\section{3- Conclusão}

O "expressionismo" leibniziano (que não deve ser confundido com um mero ecletismo) manifesta-se de modo particularmente claro em temas 
como o do valor cognitivo da experiência, que envolve a consideração dos limites do que pode ser pensado clara e distintamente. Há expressão não apenas entre sistemas filosóficos correspondentes, de tal modo que o sistema mais perfeito pode traduzir e corrigir todos os demais em si mesmo (é essa a ambição dos Novos ensaios, por exemplo), mas também entre domínios da consciência nos quais, à primeira vista ao menos, se ultrapassam os limites do conhecimento racional. De fato, de acordo com a hipótese da harmonia preestabelecida, cada mônada ou substância simples é um microcosmo que expressa toda a realidade; ao transpor essa concepção do nível ontológico para o epistemológico ${ }^{39}$, percebemos que a autocompreensão de Leibniz a respeito de seu próprio discurso filosófico envolve de modo essencial a ideia de que todas teorias, e mesmo todas as opiniões dos homens, bem como suas experiências, se entre-expressam mutuamente. A verdadeira filosofia deve, portanto, saber encontrar as leis que regem essas "traduções" 40 , pelo menos até onde isso for possível.

No começo do século XX, Ludwig Wittgenstein afirmará, com ares de evidência que só sua herança cultural romântica poderia garantir, que "há por certo o inefável. Isso se mostra, é o Místico" (WITTGENSTEIN, 6.522). Encontramo-nos aí em um horizonte teórico no qual o acesso ao místico tem muito mais as cores do spinozismo - ou, pelo menos, do Spinoza dos românticos do século XIX. Nesse novo contexto, não é a onipresença da razão humana em todo o campo da experiência - seja ela sensível ou mística - que garante a conversão entre o Real e o Racional, mas antes a doutrina segundo a qual, visando o infinito, a razão sintetiza, em sua unidade superior, tudo o que pode ser pensado - o que inclui, paradoxalmente, os limites do impensável ${ }^{41}$. Entre Wittgenstein e Maurice Blanchot, a distância é talvez mais curta do que se poderia imaginar. Nesse contexto pós-Romântico, em suma, a posição de Leibniz sobre as relações entre razão e experiência não tinha mais sentido. Será preciso esperar uma crítica ao Romantismo e suas sínteses dialéticas para que ela pudesse ser reabilitada ${ }^{42}$.

${ }^{1}$ Este texto foi escrito com o auxílio de uma Bolsa de Produtividade em Pesquisa concedida pelo CNPq. Agradeço a um parecerista anônimo da revista doispontos por suas valiosas críticas, que me ajudaram a melhorar o artigo.

doispontos, Curitiba, São Carlos, vol. 11, n. 2, p.181-208, outubro, 2014 
2 "Sententia falsissima et idem est hic error cum eo quem Cartesius insinuavit". (LEIBNIZ, 1854, p. $48)$.

3 “Cum verum vero consentiat, suspecta erit Theologia qua cum ratione pugnat" (LEIBNIZ, 1854, p. 74); citado por FRIEDMANN, 1962, p. 211.

${ }^{4}$ Sobre a concepção cartesiana de "limite da razão", cf. BEYSSADE, 2001.

${ }^{5}$ Encontrando-se na passagem entre os séculos XVII e XVIII, Leibniz encarna em sua obra as continuidades e as distinções entre esses dois períodos. De fato, segundo Cassirer, “... comparando o pensamento do século XVIII com o do século XVII, em nenhum ponto verifica-se uma verdadeira ruptura entre eles [....].A diferença que existe entre essas duas formas de pensar [....] apenas exprime uma espécie de deslocamento de acento" (CASSIRER, 1992, pp. 43-44). Ao comparar aqui Leibniz a Spinoza acerca do misticismo, devemos levar em conta essa advertência de Cassirer. Sobre o modo como esse último via a posição de Leibniz, Descartes e Spinoza em relação ao Iluminismo nascente, cf. CASSIRER, 1992, pp. 51-61.

${ }^{6}$ Cf. Animadversiones in Partem Generalem Principiorum Cartesianorum (G IV, 357). Também Spinoza recusa a dúvida dos céticos, mas mantém o projeto de fundamentação da razão em Deus; entretanto, sua crítica à legitimidade da dúvida cética é bastante diferente da de Leibniz - para ficar em um único exemplo, Spinoza não crê que os argumentos céticos elencados na Primeira Meditação encurralem Descartes em uma espécie de raciocínio circular (cf. BOLTON, 1985, pp. 379-395).

${ }^{7}$ Os textos de Leibniz contidos na edição de Gerhardt serão citados usando a abreviação G, seguida da referência ao volume em números romanos e da referência à página em números arábicos. O texto citado acima corresponde ao Capítulo 11 do Livro IV dos Nouveaux essais sur l'entendement humain. As traduções para o português dos textos de Leibniz citados neste artigo são de minha responsabilidade.

${ }^{8}$ A tradução desse trecho é minha.

${ }^{9}$ Ver, por exemplo, os textos contidos em COUDERT et. al., 1998.

${ }^{10}$ Trata-se dos $\$ \$$ 65-69 da Monadologie.

${ }^{11}$ Minha proposta vai de encontro, por exemplo, à de Friedmann (FRIEDMANN, 1962, p. 216), quando ele sugere que a crítica de Leibniz ao conceito de modo infinito formulado por Spinoza - aproximado, por Wachter, de noções da Cabala - deriva de uma espécie de "recalque" de um problema contido em sua própria doutrina, explicando assim um posicionamento conceitual através de um elemento biográfico ou psicológico.

12 Monadologie, $\$ 47$.

${ }^{13} \mathrm{Na}$ Monadologie, Leibniz afirma, porém, que a matéria é não apenas divisível ao infinito, mas que essa divisão está dada em ato. Isso pareceria, portanto, contrariar nossa afirmação, feita acima, de que o infinito em ato não é dado no interior do Mundo. Diferentemente desse infinito material, porém, o infinito em ato divino não depende de nada além de si mesmo para ser em ato; a matéria prima, ao contrário, sendo pura potência, depende das mônadas para existir atualmente como matéria secunda. Em suma, apenas Deus é um ser absolutamente infinito.

${ }^{14}$ Sobre essa denominação, ver ISRAEL, 2001. 
${ }^{15}$ A analogia entre as experiências místicas e sensíveis já foi assinalada por muitos. Para uma retomada recente dessa analogia, cf. ALSTON, 1991, especialmente quando, no cap. 1, intitulado "The Experience of God: A Perceptual Model”, ele trata de anunciar sua estratégia argumentativa: "I shall argue that if we think of perception in the most general way, in which it is paradigmatically exemplified by but not confined to sense perception, putative awareness of God exhibits this generic character" (ALSTON, 1991, p. 9).

${ }^{16}$ É notável, entretanto, que Descartes não tenha a mesma atitude relativamente à experiência mística; de fato, embora essa última não pertença à Ciência, ela produz um conhecimento mais claro e distinto do que a "luz natural da razão". Cf., sobre esse ponto, as discussões sobre a graça divina nas Réponses aux Deuxièmes Objections (A.T., IX, 115-116).

${ }^{17}$ Nouveaux essais, Prefácio.

${ }^{18}$ É isso o que vai permitir a Leibniz estabelecer, nos Eclaircissements des difficultés que Monsieur Bayle a trouvées dans le système nouveau de l'union de l'âme et du corps, (G IV, 167), que "cette multitude infinie de perceptions nous empeche de les distinguer, comme lorsque j'entends un grand bruit confus de toute un peuple, je ne distingue point une voix de l'autre" - ou seja, os pensamentos confusos não diferem por natureza dos distintos: eles são somente menos distintos e menos desenvolvidos por causa de sua multiplicidade.

${ }^{19}$ Nouveaux essais, Prefácio.

${ }^{20}$ Como se sabe, será essa homogeneidade qualitativa que despertará as críticas de Kant a Leibniz tanto na "Anfibologia dos conceitos puros de reflexão" quanto na "Estética transcendental” da Crítica da razão pura. Para uma refutação da crítica kantiana, ver PARKINSON, 1994. Parkinson introduz nuances na tese da continuidade entre razão e sensação, tentando distingui-las qualitativamente no que diz respeito ao modo como elas se manifestam em mentes finitas. Embora sua leitura seja correta, ela não deve nos cegar para a importância que o projeto filosófico leibniziano concede ao reconhecimento da continuidade entre intelecto e sensação. De fato, o estatuto cognitivo da experiência sensível só pode ser compreendido através de tal reconhecimento. Em muitos textos, tal como o citado acima na nota (18), Leibniz deve enfatizar que o termo geral "pensamento" [pensée] refere-se indistintamente a sensações e a conceitos. Nesse sentido, a interpretação de Kant não pode ser inteiramente descartada. Ver também, no contexto do diálogo com Bayle, a Addittion à l'Explication du système nouveau... (G IV, 574).

${ }^{21}$ Nouveaux essais, IV, Cap. 11.

${ }^{22}$ Se uma dúvida universal sobre os sentidos é impossível, segundo Spinoza, isso não decorre, porém, da admissão de algum valor cognitivo para as sensações, mas antes do exame racional sobre a estrutura ontológica do mundo e do papel da imaginação em nosso acesso aos objetos. Além disso, nos adverte Spinoza (Ética II, p. 48 e p. 49), as ideias obscuras e confusas da sensação vêm sempre acompanhadas de sua asserção, de tal modo que nenhuma ideia racional poderia eliminar nossa crença na existência dos objetos externos à mente, derivada dos juízos imaginativos.

23 O que enunciamos até aqui como a "posição leibniziana" relativamente à natureza do fundamento da verdade e suas relações com a experiência sensível não foi localizado em uma fase precisa de sua obra, justamente porque essa é uma tendência, acredito, que perpassa toda

doispontos, Curitiba, São Carlos, vol. 11, n. 2, p.181-208, outubro, 2014 
ela, ainda que pesem as diferenças de ênfase e o contexto teórico mais amplo em que foram formuladas.

${ }^{24}$ Cf. SPINOZA II, p. 41: "O conhecimento do primeiro gênero é a única causa de falsidade, enquanto o conhecimento do segundo gênero e o do terceiro é necessariamente verdadeiro". Seguirei aqui a tradução da Ética de Tomaz Tadeu (SPINOZA, 2008).

25 "Il avait une plaisante opinion de l'immortalité de l'âme, c'est qu'il concevait que cette idée platonique de notre être, qui est sans doute aussi éternelle que celle du cercle ou du triangle, fait proprement notre immortalité". Leibniz, Lettre à Hessen-Rheinfels (Ak., W., II, 1, p. 535) (citada por FRIEDMANN, 1962, p. 166).

${ }^{26}$ Cf. Tractatus theologico-politicus, Cap.VII, "Da interpretação da Escritura” (G III, 97-116).

${ }^{27}$ A história de tais aproximações entre a quinta parte da Ética e o misticismo tem longa tradição; Leibniz não foi, de fato, o último a suspeitar que a filosofia de Spinoza - e, especialmente, a parte $\mathrm{V}$ da Ética - não fazia mais do que se apropriar (talvez não sem um certo uso paródico) de um vocabulário místico e neo-platônico; muitos depois dele viram nessa proximidade vocabular uma verdadeira afinidade espiritual. Schopenhauer, por exemplo, no Apêndice de $O$ mundo como vontade e representação, aproxima a filosofia de Spinoza (e a de Giordano Bruno) de doutrinas orientais. "Bruno e Spinoza”, escreve aí Schopenhauer, "não pertencem ao seu século nem ao seu continente, os quais, a um recompensou com a morte, ao outro com perseguição e ignomínia. Sua existência e morte miseráveis neste Ocidente compara-se à de uma planta tropical na Europa. O verdadeiro torrão natal de seu espírito eram as margens do sagrado Ganges" (SCHOPENHAUER, 2005, p. 532). Marilena Chauí resume e critica as interpretações "orientalistas" de Spinoza, particularmente as que tentam aproximá-lo do budismo, em $A$ nervura do real (CHAUí, 1999, pp. 103-106). No capítulo 2 da parte I de seu livro, Chauí narra a constituição da imagem (ou, seria melhor dizer, das imagens) do spinozismo na cultura européia entre os séculos XVII e XIX, lembrando-nos que "Hegel, tendo afirmado a modernidade de Espinosa", logo acrescenta "que seu sistema é acosmista, e sua filosofia "eco das terras orientais' à qual "falta o princípio ocidental da individualidade" (p. 27). Já no século XX, Jonathan Bennett, em seu livro sobre Spinoza, e com sua usual falta de sutileza histórica, recusa-se a sequer comentar detidamente a parte V da Ética, por considerá-la um amontoado de insights místicos desprovidos de qualquer valor teórico. (BENNETT, 1984, pp. 372-375). Bennett enumera outros comentadores de língua inglesa (como Pollock, Hampshire, Parkinson e Broad) que interpretaram a parteV da Ética como a manifestação das tendências místicas de Spinoza; assim, por exemplo, Pollock afirma que "there is unquestionably something of an exalted and mystical temper in his expressions; and it seems possible enough that, but for his scientific training in the school of Descartes, he might have been a mystic indeed" (in: Spinoza, p. 303, apud BENNETT, 1984, p. 373). Por parte de Leibniz, tal suspeita manifesta-se sobretudo quando retoma, mais de trinta anos depois de suas detalhadas anotações de leitura da então recém-publicada Ética, feitas em 1678, a atividade de comentar mais extensamente a obra de Spinoza. A ocasião dessa retomada vigorosa de um comentário de fôlego do spinozismo se dá quando da publicação do de Wachter. Esse último, como vimos, defende a Cabala cristianizada, então em voga, inclusive em certos círculos bastante próximos de Leibniz, através de uma tese compatibilista entre o misticismo cabalista e - segundo Wachter - o spinozista. Leibniz não critica tal assimilação; ao contrário, tomando-a como correta, examina um de seus termos pelo outro.

doispontos, Curitiba, São Carlos, vol. 11, n. 2, p.181-208, outubro, 2014 
${ }^{28}$ Sobre o papel confirmatório dos signos, cf.VINCIGUERRA, 2005, p. 293: o signo [signe] é como que a assinatura [signature] de Deus garantindo o conteúdo revelado.

${ }^{29}$ Note-se bem: os fiéis acreditam na verdade dessas proposições, mas sua crença é fundamentada na fé, isto é, na obediência aos mandamentos de Deus. Só a razão pode demonstrar que essas proposições são verdadeiras - o que, dada a identificação spinozana entre verdade e demonstrabilidade, nos leva à conclusão de que o predicado "é verdadeira" só pode ser aplicado propriamente a uma proposição do ponto de vista racional.

${ }^{30}$ Cf. Tractatus theologico-politicus, capítulo VI (G III, 81-96). Nesse famoso capítulo, Spinoza adverte o leitor que ele introduz uma inversão na ordem de exposição adotada nos capítulos I e II: nesses últimos, tratava-se, primeiramente, de estabelecer o sentido literal do texto bíblico, para só depois avaliar filosoficamente sua verdade, justamente porque o fenômeno profético ultrapassa os limites do entendimento humano (isto é, pertence ao campo imaginativo); já no capítulo VI, que trata dos milagres, trata-se de um fenômeno que pode ser objeto de um discurso racional. De fato, Spinoza demonstra que a crença na existência de milagres conduz ao ceticismo e ao ateísmo - e só depois de estabelecida essa verdade é determinado o sentido (alegórico ou retórico) dos textos bíblicos. Longe de conter um procedimento circular ou dogmático (na medida em que o sentido literal do texto bíblico é aí determinado pela verdade filosófica), o capítulo VI é um modelo perfeito do procedimento filosófico do Tratado: o objetivo do livro não é erigir uma hermenêutica bíblica, mas avaliar filosoficamente os conteúdos comuns ao fenômeno religioso e à filosofia.

${ }^{31}$ Como se sabe, Spinoza exclui da Bíblia todo conhecimento especulativo acerca da natureza de Deus, restringindo seu escopo de conhecimento passível de demonstração clara e distinta às leis morais - exceção feita (não sem que isso introduza no sistema alguns problemas difíceis) de algumas verdades teóricas requeridas pelo "credo mínimo". Além disso, a Bíblia contém verdades que são apenas prováveis, dadas por seus relatos históricos.

${ }^{32}$ Cf. especialmente o texto Von der wahren Theologia mystica (LEIBNIZ, 2010). Esse opúsculo de Leibniz, redigido provavelmente entre 1698 e 1701, é o único texto dedicado exclusivamente à mística, e no qual o autor adota ele mesmo um tom um tanto exaltado, próximo da vibração dos escritos místicos, aos quais, no entanto, ele se contrapõe aí mais uma vez.

${ }^{33}$ A publicação aconteceu em 1854, sob o título, um tanto enganoso, de Réfutation inédite de Spinoza par Leibniz. A data de composição do texto varia certamente entre 1706 e 1710 (o ano mais antigo é estabelecido pelo fato de que o livro Elucidarius Cabalisticus foi publicado em 1706). Sobre as relações de Leibniz com o misticismo, é importante consultar, além das Animadversiones..., a coletânea de textos estabelecidos e publicados em 1948 por Gaston Grua na seção II ("Visionnaires et Quiétistes") do livro (G.W. Leibniz. Textes inédits d'après les manuscrits de la bibliothèque provinciale de Hanovre). Essa edição contém textos importantes de Leibniz sobre o misticismo, especialmente sua correspondência com Morell.

${ }^{34}$ Sobre isso, deve-se consultar a aproximação, feita por Wachter, entre o conceito cabalístico de "Espírito do mundo" e o conceito de modo infinito imediato do atributo Pensamento, apresentado por Spinoza na proposição 21 da parte I da Ética. É curioso notar que essa doutrina spinozista não fora examinada a fundo por Leibniz em suas anotações de juventude às margens de sua edição da Ética, o que é um índice de que o interesse do Leibniz maduro por Spinoza sofreu um deslocamento importante nesse novo contexto. Mas esse deslocamento

doispontos, Curitiba, São Carlos, vol. 11, n. 2, p.181-208, outubro, 2014 
não deve ser compreendido simplesmente como um abandono das preocupações anteriores com o determinismo, já que a crítica a esse último aparecerá de forma aguda, por exemplo, nos Ensaios de teodiceia.

35 Gilles Deleuze resume na expressão "micropercepções alucinatórias" [microperceptions hallucinatoires] essa indiferença primitiva entre o real e o fictício, o racional e o sensível. Cf. DELEUZE, 1988, p. 115.

${ }^{36}$ E esse não é, evidentemente, um exemplo qualquer, pois, como vimos, a chave de leitura de Leibniz sobre o spinozismo era o de considerá-lo uma radicalização do cartesianismo.

37 Ética I, p. 33, esc. 2: "Nam hi aliquid extra Deum videntur ponere, quod à Deo non dependet, ad quod Deus, tanquam ad exemplar, in operando attendit, vel ad quod, tanquam ad certum scopum, collimat. Quod perfectò nihil aliud est, quàm Deum fato subjecere, quo nihil de Deo absurdius statui potest, quem ostendimus tam omnium rerum essentiæ, quàm earum existentix primam, \& unicam liberam causam esse. Quare non est, ut in hoc absurdo refutando tempus consumam".

38 “Spinoza, Eth. p. 5, prop. 21, ait memoriam et imaginationem cum corpore evanescere. Sed ego censeo semper aliquam imaginationem et memoriam manere et sine illis animam nullam fore. Neque putandum est menem existere sine sensu seu anima. Ratio sine imaginatione et memoria est consequentia sine premissis".

${ }^{39}$ Na primeira intervenção de Teófilo nos Nouveaux essais (G V, 61-62), na qual discorre justamente sobre o estatuto do "sistema novo" que passará a discutir em seguida, lemos que esse sistema "... toma o melhor de cada lado, e em seguida vai mais longe do que se foi até agora". No prefácio do mesmo livro, vemos a mesma fórmula que é geralmente aplicada ao místico ser usada a respeito de Locke: “... ainda que o autor do Ensaio diga mil belas coisas que aplaudo, nossos sistemas diferem muito".

${ }^{40}$ Sobre esse ponto, cf. LEBRUN, 2006.

${ }^{41}$ Não é por acaso que o Tractatus logico-philosophicus terminará com o célebre paradoxo "minhas proposições elucidam dessa maneira: quem me entende acaba por reconhecê-las como contra-sensos [unsinnig]" (6.54) e com "sobre aquilo de que não se pode falar, deve-se calar" (7).

${ }^{42}$ Assim, por exemplo, Deleuze se aproximará tanto mais de Leibniz quanto mais se afasta do Romantismo: ele é mais leibniziano do que spinozano (sua proximidade com Spinoza, por outro lado, revela o quanto ele ainda transita em um ambiente romântico).

\title{
Referências bibliográficas
}

ALSTON,W. P. 1991. Perceiving God. The Epistemology of Religious

Experience. Ithaca and London: Cornell University Press.

\author{
BENNETT, J. 1984. A Study of Spinoza's Ethics. Cambridge: Cambridge \\ University Press,
}


BEYSSADE, J.-M. 2001. Ordre et mesure: Descartes aux limites de la raison. In: Descartes au fil de l'ordre. Paris: PUF, pp. 307-322.

BOLTON, M. B. 1985. Spinoza on Cartesian Doubt. In: Noûs, Vol. 19, No. 3 .

CASSIRER, E. 1992. A filosofia do Iluminismo. [Die Philosophie der Aufklärung] Tradução de Álvaro Cabral. São Paulo: Editora da Unicamp.

CHAUÍ, M. 1999. A nervura do real. São Paulo: Companhia das Letras.

DELEUZE, G. 1988. Le pli. Leibniz et le baroque. Paris: Éditions de Minuit.

FRIEDMANN, G. 1962. Leibniz et Spinoza. Paris: Gallimard.

ISRAEL, J. 2001. Radical Enlightenment. Philosophy and the Making of Modernity 1650-1750. Oxford: Oxford University Press.

LEBRUN, G. 2006. A noção de 'semelhança' de Descartes a Leibniz. In: A filosofia e sua história. São Paulo: Cosacnaify, pp. 433-450.

LEIBNIZ, G. W. 1854. Animadversiones ad J. G. Wachteri librum de recondita Hebraeorum Philosophice. Estabelecimento do texto e tradução de A. Foucher de Careil (Réfutation inédite de Spinoza par Leibniz). Paris: 1854, in $-8^{\circ}$.

LEIBNIZ, G.W. 1875-1890 [G]. Die philosophischen Schriften von G.W. Leibniz, C.J. Gerhardt (ed.), 7 vols. Berlin. Reedição Georg Olms, Hildesheim, 1978.

LEIBNIZ, G. W. 1923- [Ak]. Sämtliche Schriften und Briefe. Ed. Deutsche Akademie der Wissenschaften zu Berlin. Darmstad; Berlin: Akademie Verlag.

LEIBNIZ, G. W. 2010. Von der wahren Theologia mystica. In: Revue de Théologie et de Philosophie III-IV, pp. 301-319.

LEIBNIZ, G.W. 1998. Textes inédits (d'après les manuscrits de la bibliothèque provinciale de Hanovre). 2 volumes. Gaston Grua (ed.). Paris: PUF.

LEIBNIZ, G. W. 1990. Leibniz, G.W. Nouveaux essais sur l'entendement humain. Paris: Flammarion. 
MATHERON, A. 2011. La vie éternelle et le corps selon Spinoza. In: Études sur Spinoza et les philosophies de l'âge classique. Paris: Ens Éditions, pp. 693-706.

PARKINSON, G. H. R. 1994. The 'Intellectualization of Appearances': Aspects of Leibniz's Theory of Sensation and Thought. In: G. W. Leibniz - Critical Assessments, London and New York: Routledge,Vol. IV, pp. 67-86.

RUTHERFORD, D. 1998. Leibniz and Mysticism. In: COUDERT, A. P.; POPKIN, R. H.;WEINER, G. M. - Leibniz, Mysticism, and Religion. International Archives of the History of Ideas Archives internationales d'histoire des idées. Dordrecht: Kluwer.

SCHOPENHAUER, A. 2005. O mundo como vontade e representação. Tradução de Jair Barboza. São Paulo: Editora Unesp; Schopenhauers Sämtiliche Werke, Munique: PiperVerlag, 1911-1926, Bd I.

SPINOZA, B. 2008. Ética. Tradução e notas de Tomaz Tadeu. Belo Horizonte: Autêntica.

SPINOZA, B. 1908. Tractatus theologico-politicus. Übertr. und eingel. nebst Anm. und Reg. von Carl Gebhardt. 3. Aufl., Leipzig: Dürr, (Philosophische Bibliothek ; 93).

SPINOZA, B. 2008. Tratado teológico-político. Tradução de Diogo Pires Aurélio. São Paulo: Martins Fontes.

VINCIGUERRA, L. 2005. Spinoza et le signe. La genèse de l'imagination. Paris:Vrin.

WACHTER, J. G. 1706. Elucidarius Cabalisticus, sive Recondita Hebrcorum Philosophia, Brevis \& Succinta Recensio, Epitomatore Joh. Georgio Wachtero Prof. Romaæ.

WITTGENSTEIN, L. 1994. Tractatus logico-philosophicus. Tradução de Luiz Henrique Lopes dos Santos. São Paulo: Editora da USP. 